\title{
Padrão das lesões nas vítimas de acidentes de motocicleta*
}

\author{
Injury patterns in motarcycle accident victims
}

\section{Maria Sumie Koizumi*}

KOIZUMI, M.S. Padrão das lesōes nas vítimas de acidentes de motocicleta. Rev. Saúde Públ., S. Paulo, 26: 306-15, 1992. Apresenta-se uma análise do padrão das injúrias nas vítimas de acidentes de motocicleta internadas num hospital governamental de ensino, do Município de Sảo Paulo, o qual conta com um serviço de emergência de referência. Ficou confirmado que nas vítimas internadas predominam os jovens, do sexo masculino e que a grande maioria recebe alta do hospital. Quanto às injúrias, verificou-se predomínio das classificadas no grau de intensidade leve (ISS de 1 a 9) e as lesōes mais freqūentes foram as fraturas de membros e pelve, os ferimentos de superfície externa, os traumatismos crânio-encefálicos e as luxaçōes de membros e pelve. Nas que faleceram, além das fraturas de membros e pelve, as lesōes de órgãos abdominais e traumatismos crânio-encefálicos preponderaram e a ISS foi superior a 20. Nos pacientes com trauma de crânio, constatou-se relação direta entre escores altos da Escala de Coma de Glasgow e baixos da ISS e vice-versa.

Descritores: Ferimentos e lesōes, epidemiologia. Acidentes de trânsito. Motocicletas.

\section{Introdução}

O estudo do padrão das lesões nas vítimas de acidente de trânsito de veículo a motor em geral, particularmente daquelas de acidentes de motocicleta, não pode se restringir aos dados advindos do quadro de sua mortalidade. No entanto, estudos que descrevem os diferentes tipos, localizações e graus de intensidade das lesões nas vítimas de acidentes de trânsito, que morretam ou não, além de escassos são difíceis de serem realizados.

É preciso enfatizar que a proporção de feridos nos acidentes de moto é muito maior do que naqueles devido aos demais acidentes de trânsito de veículo a motor. Há autores que estimam essa proporção em cerca de $90 \%$ para os acidentes de motocicleta e $9 \%$ para os demais veículos ${ }^{9,10,11,12}$, fato também constatado no Município de São Paulo, no que se refere aos acidentes de moto ${ }^{23}$.

A vulnerabilidade do usuário da moto é evidente. Para ele não há proteções similares àquelas dos ocupantes de veículos de quatro

* Dados extraídos da Tese de Livre-Docência "Natureza das lesōes nas vítimas de acidentes de motocicleta" apresentada à Escola de Enfermagem da USP, 1990

** Departamento de Enfermagem Médico-Cirírgica da Escola de Enfermagem da Universidade de São Paulo - São Paulo, SP - Brasil

Separatas/Reprints: M.S. Koizumi - Av. Dr. Enéas de Carvalho Aguiar, 419 - 05403-000 - São Paulo, SP - Brasil

Publicação financiada pela FAPESP. Processo Saúde Coletiva 91/4994-0 rodas ${ }^{16,26}$. Na colisão, que é um dos tipos de acidentes de motocicleta mais usual, o motociclista absorve em sua superfície corpórea toda a energia gerada no impacto, seja indo de encontro com a via pública, seja com os objetos da mesma ou outros veículos a motor. Como conseqüência, há ocorrência de vítimas politraumatizadas com as lesões mais graves localizando-se na cabeça e as extremidades como as regiōes mais freqüentemente atingidas $^{16,34}$.

No estudo epidemiológico sobre acidentes de motocicleta ocorridos no Município de São Paulo, no ano de 1982, foi constatado que das 166 vitimas fatais, $64(38,55 \%)$ morreram no local do evento, $7(4,22 \%)$ a caminho do hospital e $95(57,23 \%)$ no hospital. Relacionando lesões ao tempo de sobrevida, verificou-se que a morte no local ou em menos de $24 \mathrm{~h}$ após o evento, decorreu de fratura de crânio, traumatismo internos e fratura de pescoço ou tronco e que se tratavam de politraumatizados, com uma média de 4 diagnósticos de lesões por vítima fatal ${ }^{23}$.

A proporção de mortos em relação ao total de vítimas devido ao acidente de moto foi de $3,7 \%^{23}$. A importância da gravidade das lesões neste grupo ficou demonstrada dado que cerca de $2 / 3$ de todas as vítimas fatais faleceram no periodo de $24 \mathrm{~h}$ pós-acidente. Entretanto, uma das questões não respondidas no citado estudo ${ }^{23}$, relacionou-se com o padrão das lesōes nos que sobrevivem ao acidente. 
Assim, limitando o presente estudo às vítimas de acidentes de moto que foram internadas num centro de referência para traupas, apresenta-se uma análise do padrão das lesões dessas vítimas.

\section{Material e Método}

O material de estudo foi composto pela totalidade dos pacientes internados no Hospital das Clínicas da Faculdade de Medicina da Universidade de São Paulo (HCFMUSP), no ano de 1989 , devido a acidentes de motocicleta.

Foi obtido junto à Divisão de Arquivo Médico, uma lista de todos os pacientes internados no ano em estudo e que foram codificados, pela CID - $9^{\mathbf{a}^{30}}$, como E818 (outros acidentes de veículo a motor, sem colisão) e E819 (acidentes de trânsito de veículo a motor de natureza na especificada), códigos usados naquela Divisão para os diagnósticos queda de moto e acidente de motocicleta , tais como vêm descritos nos prontuários. Nesses códigos foram ainda especificados como quarto dígito: 2 (motociclista), 3 (passageiro da motocicleta) e 9 (pessoa não identificada). Foram também incluídos na lista os pacientes que se enquadravam no código E929.0 (efeitos tardios de acidentes de veículo a motor) a fim de se rastrear aqueles pacientes que foram internados decorridos mais de um mês após o acidente, porém com a ocorrência do evento no ano em estudo.

Os prontuários dos pacientes listados foram localizados e examinados, sendo excluídos aqueles que não se enquadravam na categoria especificada ou no período do estudo, ou por estarem incompletos ou por não terem sido localizados.

Em ficha própria, foram anotados os dados de identificação do paciente (nome, idade, sexo, estado civil, ocupação, local de nascimento e de residência), de internação, de saida (alta ou óbito), dias de permanência, número e tipo de operação cirúrgica, diagnóstico de lesões, dados relativos ao momento de internação, à operação e às condições de alta hospitalar e seguimentos posteriores.

Além disso, foram também coletados dados sobre o local da ocorrência do acidente, principalmente na ficha de registro de internação, especificação quanto ao tipo e circunstâncias do acidente e uso de capacete, se condutor ou passageiro da moto.
O termo vítima foi usado para definir a pessoa que sofreu lesões corporais ou veio a falecer em conseqüência do acidente de motocicleta.

$\mathrm{Na}$ análise da natureza das lesões, foram usadas as que determinam seu tipo, localização e intensidade. As siglas dessas escalas foram mantidas no seu original em inglês, ou seja, Abbreviated Injury Scale = AIS e Injury Severity Score $=$ ISS) ${ }^{2}$.

Os diagnósticos médicos constantes nos protuários dos pacientes foram transcritos integralmente, embora já estivessem codificados pela CID-9 ${ }^{\mathrm{a} 30}$. Este cuidado foi tomado para permitir a categorização pela $\mathrm{AIS}^{2,29}$.

Para o cálculo do grau de intensidade da lesão foi utilizado o método ISS (Baker ${ }^{2}$ ). Desenvolvido como complemento da AIS, ele tem sido adotado como um padrão internacional de avaliação do grau de intensidade das injúrias dos pacientes politraumatizados. Instrumentos simplificados, nos quais cada lesão pode ser rápida e facilmente pontuada no próprio serviço de emergência, foram desenvolvidos por Greenspan e col. ${ }^{15}$, no Canadá, e por Morgan e col. ${ }^{29}$ nos Estados Unidos da América. Como Greenspan e col. ${ }^{15}$ só descrevem o instrumento que está sendo utilizado no seu serviço, enquanto que Morgan e col. ${ }^{29}$ apresentam um estudo comprovatório de sua aplicabilidade, precisão e praticidade, selecionouse este para a análise dos resultados do presente estudo.

A população de estudo foi denominada genericamente de pacientes internados devido acidentes de moto porque não houve possibilidade de distinção entre motociclistas ou passageiros da motocicleta.

$\mathrm{Da}$ lista inicial, foram identificados 205 pacientes internados no ano em estudo, devido a esta causa. Deste total, foram excluídos 7 por não estarem enquadrados nas categorias especificadas ou no periodo em estudo, 11 por terem prontuário incompleto ou por ele não ter sido localizado, após três tentativas, num espaço de três meses e 5 por ter sido verificada a existência de dois prontuários para cada paciente.

\section{Resultados e Discussão}

A relação vítimas do sexo masculino para o feminino foi igual a 6,9 , ou seja, superior àquela encontrada no estudo anterior ${ }^{23}$ que foi de 4,0 . 
A predominância do sexo masculino em todas as pesquisas sobre acidentes de motocicleta é marcante. Ela varia de $79 \%$ a $96 \% \%^{3,4,6,8,9,13,14,16,21,26,27,33}$. A do presente estudo foi de $87,4 \%$ (Tabela 1), portanto, dentro dos limites já encontrados (Tabela 1).

A idade mínima dos pacientes foi de 9 e a máxima de 54 anos e a idade média foi de 24,3 anos. Quanto às faixas etárias predominantes, elas foram praticamente as mesmas do estudo anterior. $O$ percentual dos pacientes com idade inferior a 35 anos foi de $89,0 \%$ (Tabela 1).

Tabela 1. Distribuição dos pacientes internados devido a acidentes de motocicleta segundo idade e sexo. Hospital das Clínicas da Faculdade de Medicina da VSP, 1989

\begin{tabular}{|c|c|c|c|c|c|c|}
\hline \multirow[t]{3}{*}{ Idade } & \multicolumn{4}{|c|}{ Sexo } & \multicolumn{2}{|c|}{ Total } \\
\hline & \multicolumn{2}{|c|}{ Masculino } & \multicolumn{2}{|c|}{ Feminino } & \multirow[b]{2}{*}{$\mathrm{N}$} & \multirow[b]{2}{*}{$\%$} \\
\hline & $\mathrm{N}$ & $\%$ & $N$ & $\%$ & & \\
\hline $05 H_{14}$ & 4 & $(2,2)$ & 1 & $(0,5)$ & 5 & $(2,7)$ \\
\hline $15 H 24$ & 94 & $(51,6)$ & 16 & $(8,8)$ & 110 & $(60,4)$ \\
\hline $25 H 34$ & 42 & $(23,1)$ & 5 & $(2,7)$ & 47 & $(25,8)$ \\
\hline $35 \mapsto 54$ & 19 & $(10,4)$ & 1 & $(0,5)$ & 20 & $(11,0)$ \\
\hline Total & 159 & $(87,4)$ & 23 & $(12,6)$ & 182 & $(100,0)$ \\
\hline
\end{tabular}

Alguns autores verificaram que o percentual de menores de 35 anos é superior a $90 \%{ }^{8,10}$; outros encontraram percentuais de $80 \%$ a $90 \%$ para os abaixo de $30 \operatorname{anos}^{3,9,14,26}$, além dos que detectaram percentuais de $68 \%$ a $89 \%$ para os menores de 25 anos $^{10,14,16}$. Há, portanto, unanimidade nos estudos quanto a tratar-se sempre de uma população jovem e do sexo masculino.

Os dois únicos atropelados por moto, incluídos no presente estudo, eram do sexo masculino, sendo que um tinha 9 anos e o outro, 18 anos.

Em relação às crianças, foram ainda detectadas 5 com idade inferior a 15 anos. Destas, 4 eram do sexo masculino ( 2 de 9 anos e 2 de 11 anos) e uma do sexo feminino (13 anos).

Considerando-se que, no Brasil, a idade mínima legal para obtenção da carteira de motociclista é de 18 anos, causou estranheza o fato de terem sido encontradas além, destas 5 crianças, outras 20 vítimas com idade entre 16 e 17 anos (16 do sexo masculino e 4 feminino). Acredita-se que nem todos eram passageiros da moto.

Henderson e col. ${ }^{18}$ e Wilson McDonald e $\operatorname{col}^{38}$ ao discutirem o problema dos menores de 16 anos envolvidos em acidentes de moto, alertam principalmente para a inexperiência do condutor e o grau de intensidade das lesōes, o que será comentado posteriormente.

Julga-se que, além da inexperiência que seria comum a todos os motociclistas iniciantes, o fator ilegalidade deveria ser melhor considerado. Um menor de idade dificilmente terìa condição monetária para adquirir uma moto. Então, cabe aos pais a responsabilidade de determinar quando e em que condições ele deve começar a fazer uso da motocicleta, particularmente enquanto condutor da mesma ${ }^{24}$.

Desta forma, considerando-se que o sexo e a idade são as duas variáveis que melhor caracterizam as vítimas nos acidentes de moto, e confirmando-se as predominâncias esperadas para esta população, o total de pacientes foi mantido para a análise das lesões.

Considerando-se que a natureza das lesões pode influenciar o tempo de internação do paciente, o tipo de tratamento e as condições de saída do hospital, a Tabela 2 mostra que $68,7 \%$ dos pacientes estiveram internados entre 1 e 15 dias. Aqueles que faleceram no hospital $(4,9 \%)$ estiveram internados neste período de tempo. A média de dias de internação foi de 15,8 dias por paciente, sendo que o tempo mínimo foi de um dia e o máximo de 101 dias.

Tabela 2. Distribuição dos pacientes internados devido a acidentes de motocicleta segundo dias de interna. çāo e condiçōes de saída do hospital. Hospital da Clinicas da Faculdade de Medicina da USP, 1989.

\begin{tabular}{crrrrrr}
\hline $\begin{array}{l}\text { Dias de } \\
\text { Internação }\end{array}$ & \multicolumn{2}{c}{ Alta } & \multicolumn{2}{c}{ Óbito } & & \multicolumn{2}{c}{ Total } \\
& $N$ & $\%$ & $N$ & $\%$ & $N$ & $\%$ \\
\hline $01 H \infty 2$ & 35 & $(19,2)$ & 5 & $(2,7)$ & 40 & $(22,0)$ \\
$03 H 07$ & 40 & $(22,0)$ & 2 & $(1,1)$ & 42 & $(23,1)$ \\
$08 H 15$ & 41 & $(22,5)$ & 2 & $(1,1)$ & 43 & $(23,6)$ \\
$16 H 30$ & 26 & $(14,3)$ &. &. & 26 & $(14,3)$ \\
$31 H \infty 0$ & 22 & $(12,1)$ &. &. & 22 & $(12,1)$ \\
61 ou + & 9 & $(4,9)$ &. &. & 9 & $(4,9)$ \\
\hline Total & 173 & $(95,0)$ & 9 & $(4,9)$ & 182 & \\
\end{tabular}

Outros autores obtiveram limites mínimos e máximos de dias de intenação bastante amplos. Pesquisando pacientes que sofreram queimaduras devido acidentes de trânsito, inclusive os de moto, Purdue e col. ${ }^{32}$ obtiveram um mínimo de um dia e máximo de 123 dias, com média de 26,9 dias por paciente. Para os pacientes internados devido a acidentes de 
Tabela 3. Distribuição dos pacientes internados devido a acidentes de motocicleta segundo número de internaçōes e de operaçōes cirúrgicas. Hospital das Clínicas da Faculdade de Medicina da USP, 1989.

\begin{tabular}{|c|c|c|c|c|c|c|c|c|}
\hline \multirow{3}{*}{$\begin{array}{l}\text { Operaçöes } \\
\text { Cinúrgicas }\end{array}$} & \multicolumn{6}{|c|}{ Internaçōes } & \multirow{2}{*}{\multicolumn{2}{|c|}{ Total }} \\
\hline & \multicolumn{2}{|c|}{1} & \multicolumn{2}{|c|}{2} & \multicolumn{2}{|c|}{3} & & \\
\hline & $\mathrm{N}$ & $\%$ & $\mathrm{~N}$ & $\%$ & $\mathrm{~N}$ & $\%$ & $\mathrm{~N}$ & $\%$ \\
\hline Nenhuma & 58 & $(31,9)$ & 3 & $(1,6)$ & • & $\cdot$ & 61 & $(33,5)$ \\
\hline 1 & 90 & $(49,4)$ & 3 & $(1,6)$ & 1 & $(0,5)$ & 94 & $(51,6)$ \\
\hline 2 & 13 & $(7,1)$ & 5 & $(2,7)$ & - & - & 18 & $(9,9)$ \\
\hline 3 & 3 & $(1,6)$ & 1 & $(0,5)$ & - & - & 4 & $(2,2)$ \\
\hline 4 ou + & 3 & $(1,6)$ & 2 & $(1,1)$ & - & $\cdot$ & 5 & $(2,7)$ \\
\hline Total & 167 & $(91,8)$ & 14 & $(7,7)$ & 1 & $(0,5)$ & 182 & $(100,0)$ \\
\hline
\end{tabular}

moto, Rivara e col. ${ }^{33}$ constataram um mínimo de um dia e máximo de 258 dias, com média de 19,6, e Zettas ${ }^{39}$, um mínimo de um dia e máximo de 136 dias, com média em 12,5 dias. Já Fiuza ${ }^{14}$ estudou as vítimas de acidentes de moto com traumatismo crânio-encefálico e obteve uma média de 10,7 dias de internação por paciente, sendo que a maioria dos óbitos ocorreu na primeira semana de internação. De certa forma, pôde notar-se que são os pacientes ortopédicos e os queimados que elevam os dias de permanência no hospital.

Em relação às condições de saída do hospital, $173(95,0 \%)$ receberam alta (Tabela 2). A grande maioria, ou seja, $146(80,2 \%)$ receberam alta hospitalar para casa, e destes, predominaram aqueles que retornaram para seguimento ambulatorial. Dos demais pacientes, 23 tiveram alta para outro hospital, 2 receberam alta a pedido de familiares e os 2 restantes saíram com licença hospitalar e não retornaram, configurando o abandono de tratamento.

A proporção dos que faleceram no hospital foi de 4,9\% (Tabela 2). A encontrada por Rivara e col. ${ }^{33}$ foi um pouco superior $(6,5 \%)$ e as demais foram inferiores ao do presente estudo. A de Haddad e col. ${ }^{16}$ foi de 3,9\%; de May e Morabito ${ }^{27}$ igual a 3,8\%; de Leung e $\mathrm{Chau}^{26} 2,8 \%$ e de Zettas ${ }^{39} 1,5 \%$. De qualquer maneira, verifica-se que, no geral, a proporção de óbitos após internação hospitalar é relativamente baixa.

O percentual de óbitos que ocorrem nos primeiros 29 dias pós-acidente, é de $96,9 \%$, sendo que falecem no local do evento e nas primeiras 24 h $62,3 \%$ do total, conforme já foi constatado ao efetuar a análise da mortalidade por acidente de motocicleta no Município de São Paulo 22 .

A proporção baixa de óbitos em hospital explica-se, pois, pela própria gravidade das lesões das vítimas de acidentes de moto, as quais falecem antes que ocorra a internação hospitalar, ultrapassadas as $24 \mathrm{~h}$ de atendimento no serviço de emergência.

Ainda em relação aos óbitos, como já esperado, o sexo masculino preponderou em relação ao feminino e a maior frequiência relativa à idade ocorreu na faixa de 15 a 24 anos. Assim, do total de 9 óbitos, 8 foram do sexo masculino e um do feminino. Nas faixas etárias, 6 foram de 15 a 24 anos; 2 de 25 a 34 anos e um de 54 anos.

A média de número de internações foi de 1,09 , com a maioria internando-se uma única vez $(91,8 \%)$. A variação entre número de cirurgias por paciente foi grande. Houve um minimo de uma cirurgia e um máximo de 12 , além de que cerca de um terço $(33,5 \%)$ dos pacientes não foi operado. Uma única cirurgia por paciente durante a internação foi a predominante (Tabela 3).

Dentre as operações cirúrgicas realizadas, predominaram as ortopédicas num total de 104 intervenções, seguida por 20 neurocirúrgicas e 7 buco-maxilo-faciais, se consideradas aquelas que foram, em geral, únicas por paciente. Já, nas múltiplas por paciente, a mais freqüente foi a plástica com um mínimo de um e máximo de 12 cirurgias por paciente, totalizando 28 intervenções cirúrgicas.

Assim pelos resultados apresentados nas Tabelas 2 e 3 , constata-se que a variação no tempo de internação e no número de operações realizadas certamente guardou relaçāo com a natureza das lesões, além dos outros fatores inerentes à hospitalização.

Conforme mostra a Tabela 4, as lesões mais freqüentes foram localizadas nos membros inferiores $(29,8 \%)$, na cabeça $(21,5 \%)$ e na superfície externa $(18,1 \%)$. Esta distribuição se mantém naqueles que sobreviveram. Nos que faleceram, a predominância foi observada na cabeça, seguida do abdômen e membros inferiores e pelve.

Harms $^{17}$ verificou que a cabeça, os mem- 
Tabela 4. Lesōes por regiāo corpórea nos pacientes internados devido a acidentes de motocicleta segundo à classificação da "AlS" e condiçōes de saida do paciente. Hospital das Clínicas da Faculdade de Medicina da USP, 1989.

\begin{tabular}{|c|c|c|c|c|c|c|}
\hline \multirow{2}{*}{$\begin{array}{l}\text { Regióes } \\
\text { do Corpo }\end{array}$} & \multicolumn{2}{|c|}{ Alta } & \multicolumn{2}{|c|}{ Óbito } & \multicolumn{2}{|c|}{ Total } \\
\hline & $\mathbf{N}$ & $\%$ & $\mathbf{N}$ & $\%$ & $\mathbf{N}$ & $\%$ \\
\hline Cabeça & 107 & $(21,3)$ & 12 & $(23,5)$ & 119 & $(21,5)$ \\
\hline Face & 51 & $(10,2)$ & 8 & $(15,7)$ & 59 & $(10,7)$ \\
\hline Pescoço & 2 & $(0,4)$ & $\cdot$ & $\cdot$ & 2 & $(0,4)$ \\
\hline Tórax & 6 & $(1,2)$ & 5 & $(9,8)$ & 11 & $(2,0)$ \\
\hline Abdómen & 15 & $(3,0)$ & 10 & $(19,6)$ & 25 & $(4,5)$ \\
\hline Coluna vertebral & 6 & $(1,2)$ & $\cdot$ & $\cdot$ & 6 & $(1,1)$ \\
\hline Membros superiores & 62 & $(12,3)$ & 4 & $(7,8)$ & 66 & $(11,9)$ \\
\hline Membros inferiores $\theta$ pelve & 156 & $(31,1)$ & 9 & $(17,6)$ & 165 & $(29,8)$ \\
\hline Superfície externa & 97 & $(19,3)$ & 3 & $(5,9)$ & 100 & $(18,1)$ \\
\hline Total & 502 & $(100,0)$ & 51 & $(100,0)$ & $553^{*}$ & $(100,0)$ \\
\hline
\end{tabular}

AIS - "Abbreviated Injury Scale $e^{\text {"2 }}$

* Excluidos: politraumatismo (35); alcoolizado (5)

bros inferiores e os membros superiores são as regiões corpóreas mais atingidas e que prolongam o tempo de internação e também ocasionam incapacidades permanentes. Já Haddad e col. ${ }^{16}$, utilizando uma distribuição diferente, verificaram, quanto à localização, que a dorsal foi a mais atingida $(37,7 \%)$, seguida dos membros inferiores $(23,4 \%)$, cabeça e pescoço $(20,8 \%)$ e membros superiores $(16,9 \%)$.
Associando-se o tipo de lesão e sua localização aos pacientes que receberam alta hospitalar, verifica-se que a maior ocorrência foi de fraturas de membros e pelve, seguida de ferimentos de superfície externa, traumatismos crânio-encefálicos $\mathrm{e}$, com menor incidência, de luxaçōes de membros e pelve (Tabela 5).

A elevada freqüência de lesões nos membros foi também destacada por Craig ${ }^{11}$. Ele

Tabela 5. Tipo de lesão e região corpórea nos 173 pacientes internados devido a acidentes de motocicleta que receberam alta hospitalar. Hospital das Clinicas da Faculdade de Medicina da USP, 1989

\begin{tabular}{|c|c|c|c|c|c|c|c|c|}
\hline \multirow[t]{2}{*}{ Tipo de lesão } & $\begin{array}{l}\text { Cabeça e } \\
\text { pescoço }\end{array}$ & Face & Tórax & Abdómen & $\begin{array}{l}\text { Membros } \\
\text { e pelve }\end{array}$ & $\begin{array}{l}\text { Superticie } \\
\text { externa }\end{array}$ & \multicolumn{2}{|c|}{ Total } \\
\hline & N $\%$ & N $\%$ & $\mathrm{~N} \%$ & N $\%$ & N $\%$ & $\%$ & $N$ & $\%$ \\
\hline Fratura & 17 & 26 & 3 & 2 & 155 & . & 203 & $(40,4)$ \\
\hline Ferimento & - & - & - & 1 & - & 82 & 83 & $(16,5)$ \\
\hline TCE & 53 & - & - & - & - & - & 53 & $(10,6)$ \\
\hline Luxaçảo & 1 & - & 1 & - & 32 & - & 34 & $(6,8)$ \\
\hline Hematoma & 18 & 11 & - & 2 & - & . & 31 & $(6,2)$ \\
\hline Contusão & 9 & - & 1 & - & 7 & - & 17 & $(3,4)$ \\
\hline Hemorragia & 1 & 8 & 2 & 1 & - & - & 12 & $(2,4)$ \\
\hline $\begin{array}{l}\text { Trauma, laceraçāo, } \\
\text { rotura e perfuraçāo }\end{array}$ & - & 2 & - & 10 & - & - & 12 & $(2,4)$ \\
\hline Afundamento & 8 & 2 & - & - & - & - & 10 & $(2,0)$ \\
\hline Lesão ligamento & - & - & - & - & 9 & - & 9 & $(1,8)$ \\
\hline $\begin{array}{l}\text { Escara, úlcera e } \\
\text { necrose }\end{array}$ & - & - & - & - & 9 & - & 9 & $(1,8)$ \\
\hline Queimaduras & - & - & - & - & - & 6 & 6 & $(1,2)$ \\
\hline Lesāo vasos & 1 & - & - & - & 4 & - & 5 & $(1,0)$ \\
\hline Disjunçăo & . & - & - & - & 5 & - & 5 & $(1,0)$ \\
\hline $\begin{array}{l}\text { Lesão medula e } \\
\text { nervos }\end{array}$ & 1 & - & - & - & 2 & - & 3 & $(0,6)$ \\
\hline Outros & 1 & 2 & 2 & 1 & 4 & - & $10^{* *}$ & $(2,0)$ \\
\hline Total & $110(21,9)$ & $51(10,2)$ & $9(1,8)$ & $17(3,4)$ & $227(43,4)$ & $88(19,3)$ & $502^{*}$ & $(100,0)$ \\
\hline
\end{tabular}


constatou ainda que nas 104 vítimas de acidentes de moto que sobreviveram, só nos membros inferiores elas perfizeram 136 de um total de 199 lesões. A distribuição foi similar, tanto no membro esquerdo como no direito, sendo um pouco maior nas lesões mínimas à esquerda. O local mais atingido foi o joelho.

Do seu estudo Craig ${ }^{11}$ concluiu que as injúrias dos membros inferiores são as maiores causas de morbidade e permanência prolongada no hospital, o que também está em consonância com os resultados aqui obtidos. Sobretudo, há unanimidade entre os autores de que as fraturas dos membros, principalmente dos inferiores, são as principais lesões nos casos não fatais ${ }^{8,12,13,16,39}$.

Já Dodson ${ }^{12}$ constatou, quanto ao tipo e localização das lesões, que $35 \%$ dos pacientes tiveram ferimentos de superfície externa, $21,7 \%$ fraturas de membros e 9,3\% trauma craniano e que o mais comum foi o paciente apresentar lesões múltiplas. Assim 72\% daqueles com fraturas tinham outras lesões associadas. Conforme descrito anteriormente, a média de lesões nos pacientes que receberam alta hospitalar foi de 3,07. Assim lesões múltiplas foram também situação comum no presente estudo.

Ainda em relação a este segmento corpóreo, as luxaçōes foram também freqüentes nos membros inferiores e na pelve. Das 32 luxações detectadas, 10 foram de quadril. Houve ainda nesta regiāo, 5 disjunçōes especificamente localizadas na sínfise pública e na região sacroilíaca (Tabela 5).

Suraci $^{36}$ verificou que de 38 pacientes com luxação de quadril, 7 eram motociclistas. Ele encontrou como lesōes associadas a fratura de ossos pélvicos, a lesão craniana e as lesões torácicas, especificamente a contusão de miocárdio e o pneumotórax. Chama a atenção para a associação direta com lesão de nervo ciático e lesão de vaso femoral.

No presente estudo, as lesões associadas mais freqüentes foram fraturas de ossos pélvicos e de membros inferiores.

Para segurança passiva na prevenção de lesões dos membros inferiores, existe equipamento chamado protetores de pernas, acoplado na motocicleta. Entretanto, há resultados contraditórios quanto à sua efetividade. Craig e col. " não constaram redução na incidência e tampouco na gravidade das lesões de membros inferiores. Ross ${ }^{34}$, por outro lado, obteve resultados que sugerem que essas barras provêem medida de proteção, particularmente se o impacto for lateral.

Os ferimentos da superfície externa foram a segunda lesāo mais freqüente nos pacientes que receberam alta hospitalar e estavam descritos como lacerações, contusões, escoriações ou ferimentos corto-contusos. Estavam localizados principalmente nos membros inferiores.

Resultado semelhante foi obtido por May e Morabito ${ }^{27}$ que detectaram nos 213 pacientes estudados, 500 lesões descritas como laceração, contusão ou escoriação. Como o objetivo do estudo era analisar as lesões e o uso do capacete no momento do acidente, elas constataram que naqueles com capacete houve total de 124 ferimentos de superfície externa, num total de 240 lesões, e nos sem capacete, 376 ferimentos para um total de 765 lesōes todos os tipos. Assim, mesmo nos ferimentos de superfície externa, aqueles sem capacete apresentaram uma relação maior do que aqueles com este equipamento.

Associando-se o tipo de lesão e sua localização aos que faleceram, verifica-se que há predomínio de fraturas de membro e pelve, seguido de trauma, laceração ou rotura de órgãos abdominais e traumatismos crânio-encefálicos (Tabela 6).

Embora não haja menção de associação com fraturas de membros, Haddad e col. ${ }^{16}$, Leung e $\mathrm{Chau}^{26}$ e Zettas ${ }^{39}$ verificaram que os traumas abdominais e os traumatismos cranianos foram as lesões mais freqüentes nos que morreram no hospital.

Verifica-se, pois, que as fraturas de membros estendem-se também aos que faleceram no hospital e que o trauma craniano também é uma constante, tanto nos que receberam alta como nos que morreram.

O traumatismo crânio-encefálico foi a terceira lesão mais freqüente nos que tiveram alta hospitalar (Tabela 5) e a segunda nos que faleceram, se somadas aos traumatismos crânio-encefálicos, as fraturas de crânio (Tabela 6).

Nas vítimas de acidentes de motocicleta, a relação entre o trauma craniano e o uso de capacetes é freqüentemente investigada. Causou estranheza o fato de não haver nos prontuários menção quanto ao uso de capacetes, embora na maioria dos pacientes houvesse dados que indicavam que o acidente havia ocorrido recentemente, em geral, no intervalo de poucas horas. Somente em um dos prontuários havia registro de que a vítima não usava capacete.

Bried e col. ${ }^{4}$ analisaram 71 vítimas de acidentes de moto que foram internadas e so- 
Tabela 6. Tipo de lesão e regiäo corpórea afetada nos 9 pacientes intemados devido a acidentes de motocicleta, que faleceram no hospital. Hospital das Clínicas da Faculdade de Medicina da USP, 1989

\begin{tabular}{|c|c|c|c|c|c|c|c|c|c|c|c|c|c|c|}
\hline \multirow[t]{2}{*}{ Tipo de lesão } & \multicolumn{2}{|c|}{$\begin{array}{l}\text { Cabeça } \theta \\
\text { pescogo }\end{array}$} & \multicolumn{2}{|c|}{ Face } & \multicolumn{2}{|c|}{ Tórax } & \multicolumn{2}{|c|}{ Abdómen } & \multicolumn{2}{|c|}{$\begin{array}{l}\text { Membros } \\
\text { e pelve }\end{array}$} & \multicolumn{2}{|c|}{$\begin{array}{l}\text { Superficie } \\
\text { externa }\end{array}$} & \multicolumn{2}{|c|}{ Total } \\
\hline & $N$ & $\%$ & $\mathrm{~N}$ & $\%$ & $\mathrm{~N}$ & $\%$ & $\mathbf{N}$ & $\%$ & $N$ & $\%$ & $\mathbf{N}$ & $\%$ & $N$ & $\%$ \\
\hline Fratura & 2 & & 2 & & - & & - & & 12 & & $\cdot$ & & 16 & $(31,4)$ \\
\hline $\begin{array}{l}\text { Trauma, laceraçāo, } \\
\text { rotura }\end{array}$ & $\cdot$ & & - & & - & & 8 & & - & & - & & 8 & $(15,7)$ \\
\hline TCE & 6 & & - & & - & & $\cdot$ & & $\cdot$ & & $\cdot$ & & 6 & $(11,8)$ \\
\hline Hematoma & 1 & & 3 & & - & & - & & - & & $\cdot$ & & 4 & $(7,8)$ \\
\hline Hemorragia & $\cdot$ & & 2 & & 2 & & $\cdot$ & & $\cdot$ & & $\cdot$ & & 4 & $(7,8)$ \\
\hline Ferimento & $\cdot$ & & $\cdot$ & & $\cdot$ & & $\cdot$ & & - & & 3 & & 3 & $(5,9)$ \\
\hline Edema & 2 & & $\cdot$ & & $\cdot$ & & $\cdot$ & & - & & - & & 2 & $(3,9)$ \\
\hline Contusão & 1 & & $\cdot$ & & $\cdot$ & & $\cdot$ & & 1 & & - & & 2 & $(3,9)$ \\
\hline Afundamento & $\cdot$ & & - & & 2 & & - & & - & & - & & 2 & $(3,9)$ \\
\hline Outros & $\cdot$ & & 1 & & 1 & & 2 & & $\cdot$ & & $\cdot$ & & $4^{\text {t**}}$ & $(7,8)$ \\
\hline Total & 12 & $3,5)$ & 8 & $5,7)$ & 5 & 8) & 101 & $9,6)$ & 13 & $25,5)$ & & & $51 *$ & $(100,0)$ \\
\hline
\end{tabular}

breviveram; $75 \%$ não usavam capacete e $24 \%$ estavam em niveis sanguíneo de álcool acima do legal. Constatou-se que os motociclistas sem capacete tiveram maior risco de ter um traumatismo crânio-encefálico $(p<0,1)$.

May e Morabito ${ }^{27}$ analisaram 213 vítimas de acidentes de moto, sendo que $60(28 \%)$ usavam capacetes e 153 (72\%) não faziam uso deste equipamento de segurança. Nos últimos, o traumatismo craniano foi mais freqüente, tendo sido constatada diferença estatisticamente significante ao nível de $1 \%$ quando comparado aos com capacete.

Verifica-se, pois, que nos estudos mais recentes há resultados comparativos que comprovam que também naqueles que sobreviveram ao acidente a utilização do capacete tem sido benéfica, principalmente no que se refere ao menor risco de sofrer trauma de crânio.

A face foi a quarta região mais atingida, tanto nos que faleceram no hospital como naqueles que sobreviveram, sendo que a lesão predominante foi a fratura. A seguir, os hematomas e as hemorragias foram as lesões mais freqüentes, particularmente os hematomas palpebrais e as hemorragias nasais e de ouvido.

Fraturas de face, associadas ou nảo a fraturas de crânio, foram também constatadas por Cannel e col. ${ }^{7}$. Das 56 vítimas de acidentes de moto ocorridos no tráfego urbano, verificaram que $49 \%$ dos sobreviventes apresentavam trauma de crânio. Ferimentos faciais foram observados em $38 \%$ deles e $11 \%$ tinham fraturas de face ou dentes. Acrescente-se que os motociclistas com capacete sem proteção facial tive- ram mais lesões de face do que aqueles que usavam capacetes com proteção facial plena.

Em relação aos hematomas, quanto a palpebrais uni ou bilaterais, todos eles associados a traumatismos crânio-encefálicos ou trauma facial, a incidência foi de $12(6,6 \%)$, ou seja, uma freqüência relativamente baixa. Foi encontrado somente um caso de lesão ocular especificado como lesão de canalículo. Embora no presente estudo não tenha sido detectada lesão do nervo óptico ou nos demais nervos oculares, isto parece não ser um fato singular nos acidentes de motocicleta. Keane ${ }^{19}$, numa revisão de 96 pacientes vítimas de acidentes de moto com lesões oftálmicas, verificou que danos no nervo óptico e em cada um dos nervos oculares motores foram comuns e atingiram um total de 153 lesões. Afirma esse autor que a ocorrência de lesōes frontal ou frontolateral nos traumas cranianos fechados é freqüente e que ela pode estar associada a lesões dos nervos cranianos superiores, concluindo que esses resultados sāo similares nos traumas cranianos fechados de qualquer tipo, com exceção de paralisia do nervo troclear, cuja maior incidência foi constatada nas vítimas de acidentes de moto.

Ainda junto ao segmento cefálico, observou-se que dois pacientes apresentaram lesões de pescoço, sem fratura e sobreviveram (Tabela 5). Um deles apresentou lesão alta de plexo braquial e, o outro, luxação unilateral em C6-C7, sem lesão neurológica. No presente estudo não se constatou óbitos devido a lesões de pescoço. 
Em relação à lesão de plexo braquial, Andrew $^{1}$ analisou 156 pacientes internados devido a acidentes de moto e verificou também baixa incidência, ou seja, dois casos.

A lesão de plexo braquial é descrita como uma injúria característica de motociclistas que se acidentam. Seu mecanismo reflete a grande exposição do condutor no momento do impacto, seja indo de encontro com outro veículo ou com a própria via pública, e as manobras que ele usa para não ser projetado do veículo ou se proteger do impacto propriamente dito. Segundo Bull ${ }^{5}$, a paralisia subseqüente pode ser reversível, mas muitos ocasionam incapacidades graves ou permanentes.

Rosson $^{35}$ recuperou dados de 116 pacientes que haviam sido atendidos em um hospital devido à lesão de plexo braquial por acidente de motocicleta. Analisou as respostas obtidas de 106 deles e verificou que a maioria era jovem, do sexo masculino e com limitada experiência em dirigir motos. Os condutores com menos de um ano de experiência foram mais acidentados na ausência de outro veículo do que aqueles mais experientes. Do seu estudo, ele conclui que a associação entre o acidente de moto e a lesão de plexo braquial é tal que a efetiva prevenção destes acidentes poderia virtualmente erradicar este tipo de lesão.

No presente estudo, foram detectadas fraturas de coluna vertebral (Tabela 5) em 5 pacientes e todos sobreviveram. Tais fraturas foram descritas como em cunha de T9-T10, sem lesão neurológica; fratura em cunha de C5, sem alteração neurológica; fratura de processos transversos de L3-LA; fratura mais achatamento de $\mathrm{L} 1$ com lesão neurológica. Somente neste último foi anotado que na alta, o paciente apresentava paraparesia crural.

$\mathrm{Na}$ análise da mortalidade, feita no estudo anterior, verificou-se que as lesōes de pescoço eram devidas em getal a fraturas com lesão medular e que a morte ocorreu no local ou em menos de $24 \mathrm{~h}$ após o evento, ou seja, havia uma relação entre o grau de intensidade da lesão e a sobrevida.

Em relação aos que sobreviveram, May e Morabito ${ }^{27}$ também encontraram uma proporção baixa como a do presente estudo. Elas verificaram que de 240 lesōes apresentadas por 60 vítimas que usavam capacetes, 8 eram de fraturas de coluna, sendo 2 com e 6 sem lesões medulares. Em 756 lesões, das 153 vítimas que não usavam capacetes foram constatadas 12 fraturas, sendo 2 com e 10 sem lesões medulares. Os citados autores não relataram nenhum caso de lesão de plexo braquial.

Conforme pode ser visto na Tabela 7 , a maioria dos pacientes foi classificada como tendo tido lesão de intensidade leve, ou seja, com escore de 1 a 9 . Resultados em que a maioria dos pacientes apresentava ISS leve foram também constados por outros autores.

Craig e col. ${ }^{11}$ verificaram que num total de 199 lesões nas 140 vítimas de acidentes de moto, $72 \%$ foram classificadas como leve, $18 \%$ como moderada e $9 \%$ como grave. Rivara e col. ${ }^{33}$ verificaram que quase metade dos pacientes (49\%) tinha ISS menor que $15 \mathrm{e}$ $15 \%$, maior que 25 .

Pela Tabela 7 verifica-se ainda que houve relação entre a intensidade da lesão e a faixa etária. Retirando-se aqueles de 5 a 14 anos, que foi em número muito baixo, verifica-se que a proporção de lesões leves foi um pouco maior nas faixas jovens e o inverso ocorreu na proporção moderada. Não foram encontrados estudos que tivessem detectado resultados semelhantes.

Já em relação às crianças, verifica-se que existem análises mais detalhadas. Assim, em relação ao grau de intensidade das lesões em crianças, Henderson e col. ${ }^{18}$ e Wilson McDonald e col. ${ }^{38}$ afirmam que elas apresentam lesões mais graves do que os adultos. No primeiro estudo foram analisadas 10 crianças

Tabela 7. Classificação da gravidade dos pacientes internados devido a acidentes de motocicleta segundo escala de intensidade da lesão e idade. Hospital das Clínicas da Faculdade de Medicina da USP, 1989

\begin{tabular}{|c|c|c|c|c|c|c|c|c|c|c|}
\hline Intensidade & & & & & & & & & & otal \\
\hline da lesão & & $H 14$ & & $H 24$ & 25 & $H 24$ & & $H 54$ & & \\
\hline & $\mathrm{N}$ & $\%$ & $\mathrm{~N}$ & $\%$ & $\mathrm{~N}$ & $\%$ & $\mathrm{~N}$ & $\%$ & $\mathrm{~N}$ & $\%$ \\
\hline $01 H \infty$ & 3 & $(60,0)$ & 70 & $(63,6)$ & 28 & $(59,6)$ & 10 & $(50,0)$ & 111 & $(61,0)$ \\
\hline $10 \mapsto \infty$ & 2 & $(40,0)$ & 25 & $(22,7)$ & 16 & $(34,0)$ & 7 & $(35,0)$ & 50 & $(27,5)$ \\
\hline 20 ou + & - & - & 15 & $(13,6)$ & 3 & $(6,4)$ & 3 & $(15,00)$ & $21^{*}$ & $(11,5)$ \\
\hline Total & 5 & $(100,0)$ & 110 & $(100,0)$ & 47 & & 20 & $(100,0)$ & 182 & $(100,0)$ \\
\hline
\end{tabular}

- Inclui 9 óbitos 
com idade inferior a 16 anos, detectando-se ISS variando de 5 a 34 , com média em 13. No segundo, verificou-se que em 24 crianças igualmente com idade inferior a 16 anos, os escores variaram de 1 a 14, com média em 6 . Nos dois estudos as lesōes predominaram nos membros inferiores.

Conforme descrito na metodologia, pela ISS foi determinado o índice de letalidade definido como LD50, ou seja, lesões de intensidade igual à dose letal para $50 \%$ dos pacientes com aquele grau de injúria. Concomitatemente, foi determinada também a correlação entre a idade e a intensidade da lesão, sendo a LD50 preconizada como ISS de 40 para as idades de 15 a 44 anos, de 29 para as de 45 a 64 anos e de 20 para aquelas com 65 anos ou mais ${ }^{15,28}$.

No presente estudo, dos 21 pacientes com escore acima de 20,9 faleceram. Destes, 8 eram da faixa etária de 15 a 44 anos e seus escores foram, respectivamente, $25,25,29$, $35,38,43,50$ e 50 . O outro paciente tinha 54 anos e seu escore foi de 26 . Conforme se pode constatar por estes dados, o número não elevado de pacientes que faleceram no hospital mostra que de 9 pacientes, 4 enquadraram-se na LD50.

Todos os pacientes que faleceram no hospital tinham ISS superior a 20. Nesse sentido, Kumar e Paul ${ }^{25}$, estudando 51 casos fatais de trauma pélvico-abdominal devidos a acidentes de trânsito em geral, verificaram que a mortalidade foi mínima quando o escore era menor que 20 , mas acima disso havia uma correlação linear entre a elevação do escore e a mortalidade. Nos dois casos por eles detectados com ISS menor que 20, a morte ocorreu por complicações secundárias e não pelo trauma em si e após um longo período de internação.

Um dos parâmetros para pontuação do segmento cabeça e pescoço é o nível de consciência do paciente. Em geral, a pontuação é feita pela escala de Glasgow, proposta por Teasdale e Jennet ${ }^{37}$, em 1974, e que é adotada mundialmente como padrão de avaliação do nível de consiência ${ }^{20}$.

No presente estudo, o nível de consciência dos pacientes com traumas cranianos foi geralmente descrito com o uso da Escala de Coma de Glasgow, no momento da admissão da vítima no Serviço de Emergência. Assim, dos 43 pacientes que tinham registro de pontuação de Glasgow, 13 apresentaram ISS de 1 a $9 ; 18$ pacientes, de 10 a 20 , e 12 pacientes, acima de 20 .
Embora o número de pacientes tenha sido baixo, observou-se uma correlação entre niveis altos de Glasgow, ou seja, de 15 a $13 \mathrm{com}$ a maioria tendo ISS classificada como leve (11 dos 13 pacientes) e também com Glasgow menor que 8 e ISS na intensidade grave (10 dos 12 pacientes). Já naqueles com ISS de intensidade moderada houve maior distribuição, porém os pacientes localizaram-se mais em Glasgow de 15 a 13 (10 dos 18 pacientes). Esta correlação nos limites inferiores e superiores de nivel de consciência, acompanhada pela ISS em sentido inverso, foi também observada por Pal e col. ${ }^{31}$. Esses autores constataram sobretudo que pela Escala de Coma de Glasgow e pela ISS, nas seis primeiras horas após o acidente, pode-se fazer o prognóstico do tipo de alta dos pacientes com traumas cranianos.

Rivara e col..$^{33}$ verificaram que 61 (57\%) dos 107 pacientes internados por acidentes de moto apresentavam trauma craniano. Destes, 33 tinham ISS leve, com Glasgow de 13 a 15; 11 eram de intensidade moderada, com Glasgow de 9 a 12; e 17, grave, com Glasgow menor que 9. Houve 7 óbitos e 18 pacientes ficaram gravemente incapacitados ou estavam em estado vegetativo persistente na ocasião da alta hospitalar.

Conclui-se que o presente estudo confirma achados que não são novos, demonstrando que o problema existe no País e é tão importante e danoso como nos outros locais onde ele foi pesquisado.

\section{Agradecimento}

À Divisão de Arquivo Médico do Hospital das Clínicas da Faculdade de Medicina da USP, pelos dados dos pacientes internados devido acidentes de motocicleta.

KOIZUMI, M.S. [Injury patterns in motorcycle accident victims]. Rev. Saúde públ., S. Paulo, 26: $306-15,1992$. An analysis of the injury patterns presented by inpatients of a government teaching hospital, known as one of the emergency centers of S. Paulo city, Brazil, is given the majority of victims are young, male adults and most of them were later discharged from the hospital. In relation to the injuries the majority of the patients were classified as being of minor injury grade (ISS between 1 and 9) and the most frequent injuries were extremity and pelvic fractures, surface trauma, traumatic brain injury and extremity and pelvic dislocations. Besides extremity and pelvic fractures, the victims who died showed abdominal organ injury and traumatic brain injury and the ISS 
was over 20. Head injury patients who had a high Glasgow Coma Scale score had a low ISS and vice-versa.

Keywords: Wounds and injuries, epidemiology.

Accidents, traffic. Motorcycles.

\section{Referênclas Bibliográficas}

1. ANDREW, T.A. A six-month review of motorcycle accidents. Injury, 10: 317-20, 1979.

2. BAKER, S.P. et al. The injury severity score: a method for describing patients with multiple injuries and evaluating emergency care. J. Trauma, 14: 187-96, 1974.

3. BRAY, T. Cost of orthopedic injuries sustained in motorcycle accidents. J. Amer. med. Ass., 254: 2452-3, 1985

4. BRIED, J. M. et al. Medical and economic parameters of motorcycle induced trauma. Clin. Orthop., 223: 252-6, 1987.

5. BULL, J.P. Disabilities caused by road traffic accidents and their relation to severity scores. Accid Anal. Prev., 17: 387-97, 1985.

6. CAIN, C.M. et al. Cervical spinal injuries in road traffic crashes in South Australia, 1981-86. Aust. N.Z. J. Surg., 59: 15-9, 1989.

7. CANNEL, $H$. et al. Head and facial injuries after low-speed motorcycle accidents. Brit. J. Oral Surg., 20: $183-91,1982$

8. CARR, W. P. et al. Injury pattems and helmet effectiveness among hospitalized motorcyclists. Minn. Med. 64: 521-7, 1981.

9. CARROL C.L. \& WALLER, P.F. Analysis of fatal and non-fatal motorcycle crashes and comparisons with passenger cars. Chapel Hill, Highway Safety Research Center/University of North Carolina, 1980.

10. COOKRO, D.V. Motorcycle safety: an epidemiologic view. Ariz Med, 36 605-7, 1979.

11. CRAIG, G.R. et al. Lower limb injuries in motorcycle accidents. Injury, 15: 163-6, 1983.

12. DODSON Jr., C.F. Motorcycle injuries: problem without solutions. J. Arkansas. Med. Soc., 73: $115-9,1976$.

13. EDNA, T.H. \& CAPPELEN, J. Retum to work and social adjustment after traumatic head injury. Acto Neurochir., 85: 40-3, 1987.

14. FIUZA, R.M. Traumatismo craniencefálico em acidentes de motocicleta. Arq. bras. Neurocir., 7; 191-201, 1988.

15. GREENSPAN, L. et al. Abbreviated injury scale and injury severity score: a scoring chart. $J$. Trauma, 25: 60-4, 1985.

16. HADDAD, J.P. et al. Motorcycle accidents: a review of 77 patients treated in a three month period. $J$. Trauma, 16: 550-7, 1976.

17. HARMS, P.L. Injury patterns of motorcyclists involved in accidents. Crowthome, Transport and Road Research Laboratory, 1981. (TRRL - Suplementary Report, 651).

18. HENDERSON, S.A. et al. Death and serious injury in child motorcyclists. Brit. med. J, 294, n. 6582, p. 1259, 1987.

19. KEANE, J.R Neurologic eye signs following motorcycle accidents. Arch. Neurol., 46: 761-2, 1989.

20. KNIGHT, R.L. The Glasgow coma scale: ten years after. Crit. Care Nurse, 6 (3): 65-71, 1987.
21. KOIZUMI, M.S. Acidentes de motocicleta no Município de São Paulo, SP (Brasil). 1. Caracterização do acidente e da vítima. Rev. Saúde públ., S. Paulo 19: 475-89, 1985.

22. KOIZUMI, M.S. Acidentes de motocicleta no Município de São Paulo, SP (Brasil). 2. Análise da mortalidade. Rev. Saúde públ., S. Paulo 19: 543-55, 1985.

23. KOIZUMI, M.S. Aspectos epidemiológicos dos acidentes de motocicleta no Municipio de São Paulo, 1982. São Paulo, 1984. [Tese de Doutorado Faculdade de Saúde Puiblica da USP].

24. KOIZUMI; M.S. Natureza das lesões nas vitimas de acidentes de motocicleta. São Paulo, 1990. [Tese de Livre-Docencia - Escola de Enfermagem da USP].

25. KUMAR, B. \& PAUL, G. Injury severity score (ISS) as a yardstick in assessing the severity an mortality of various abdomino-pelvic trauma hospitalized victims: a clinical vis-à-vis autopsy study. Med Sci. Law, 29: 333-6, 1989.

26. LEUNG, P.C. \& CHAU, B.T.N. Motorcycle accidents in Hong Kong-pattem of injury, treatment, causative factors and socio-economic implications. Injury, 15: 23-9, 1983.

27. MAY, C. \& MORABITO, D. Motorcycle helmet use, incidence of headi injury, and cost of hospitalization. J. emerg. Nurs., 15: 389-92, 1989.

28. McGINNIS, G.S. An introduction to injury severity scaling. J. neurosci. Nurs., 21: 201-3, 1989.

29. MORGAN, T.O. et al. Injury severity scoring: influence to timing and nurse raters on accuracy. Heart Lung, 17: 258-61, 1988.

30. ORGANIZAÇÁ MUNDLAL DE SAÚDE. Manual da classificação estatistica internacional de doenças, lesões e causas de óbito: 9" revisão, 1975. São Paulo. Centro da OMS para Classificação de Doenças em Português, 1980 . v.1.

31. Pal, J. et al. The value of the Glasgow coma scala and injury severity score: predicting outcome in multiple trauma patients with head injury. $J$. Trauma, 29: 746-8, 1989.

32. PURDUE, G.F. et al. Bums in motor vehicle accidents. J. Traume, 25: 216-9, 1985.

33. RIVARA, F.P. et al. The public cost of motorcycle trauma. J. Amer, med Ass., 260: 221-3, 1988.

34. ROSS, D.J. The prevention of leg injuries in motorcycle accidents. Injury, 15: 75-7, 1983.

35. ROSSON, J. W. Closed traction lesions of the brachial plexus: an epidemic among motorcyclists. Injury, 19: 4-6, 1988.

36. SURACl, A.J. Distribuition and severity of injuries associated with hip dislocations secondary to motor vehicle accidents. J. Trauma, 26: 458-60, 1986.

37. TEASDALE, G. \& JENNET, B. Assessment of coma and impaired cousciousness: a practical scale. Lancet, 2: $81-3,1974$.

38. WILSON MacDONALD, J. et al. Off-the-road motorcycling injuries 1982 1985. Injury, 18: 196-8, 1987.

39. ZETTAS, J.P. et al. Injury patterns in motorcycle accidents. J. Trauma, 19: 833-6, 1979.

Recebido para publicaçāo em 3.4.1992

Reapresentado em 26.5.1992

Aprovado para publicação em 28.5.1992 